\title{
Factors associated with the patient safety climate at a teaching hospital $^{1}$
}

\author{
Raíssa Bianca Luiz² \\ Ana Lúcia de Assis Simões ${ }^{3}$ \\ Elizabeth Barichello ${ }^{4}$ \\ Maria Helena Barbosa ${ }^{3}$
}

Objectives: to investigate the association between the scores of the patient safety climate and socio-demographic and professional variables. Methods: an observational, sectional and quantitative study, conducted at a large public teaching hospital. The Safety Attitudes Questionnaire was used, translated and validated for Brazil. Data analysis used the software Statistical Package for Social Sciences. In the bivariate analysis, we used Student's t-test, analysis of variance and Spearman's correlation of $(a=0.05)$. To identify predictors for the safety climate scores, multiple linear regression was used, having the safety climate domain as the main outcome $(a=0.01)$. Results: most participants were women, nursing staff, who worked in direct care to adult patients in critical areas, without a graduate degree and without any other employment. The average and median total score of the instrument corresponded to 61.8 $(S D=13.7)$ and 63.3, respectively. The variable professional performance was found as a factor associated with the safety environment for the domain perception of service management and hospital management $(p=0.01)$. Conclusion: the identification of factors associated with the safety environment permits the construction of strategies for safe practices in the hospitals.

Descriptors: Patient Safety; Safety Management; Health Personal.

\footnotetext{
1 Paper extracted from master's thesis "The patient safety culture in a teaching hospital of Minas Gerais" presented to Universidade Federal do Triângulo Mineiro, Uberaba, MG, Brazil. Supported by Fundação de Amparo à Pesquisa do Estado de Minas Gerais (FAPEMIG), Brazil, process \# APQ-02222-12.

2 MSc.

3 PhD, Associate Professor, Universidade Federal do Triângulo Mineiro, Uberaba, MG, Brazil.

${ }^{4}$ PhD, Adjunct Professor, Universidade Federal do Triângulo Mineiro, Uberaba, MG, Brazil.
}

Corresponding Author: Maria Helena Barbosa Universidade Federal do Triângulo Mineiro Av. Getúlio Guaritá, 107 Bairro: Abadia CEP: 38025-440, Uberaba, MG, Brasil E-mail: mhelena331@hotmail.com, mhelena@enfermagem.uftm.edu.br
Copyright @ 2015 Revista Latino-Americana de Enfermagem This is an Open Access article distributed under the terms of the Creative Commons Attribution Non-Commercial License (CC BY-NC).

This license lets others distribute, remix, tweak, and build upon your work non-commercially, and although their new works must also acknowledge you and be non-commercial, they don't have to license their derivative works on the same terms. 


\section{Introduction}

The occurrence of adverse events entails countless losses related to the patient, such as disabilities, physical and psychological trauma, increased length of hospital stay and distancing from society and work. These losses do not only relate to the patient, but also to the professionals, who have ethical and moral damages, and losses in professional-patient interaction(1). For health institutions, the adverse events (AEs) cause increased costs, loss of confidence in the institution, as well as moral and organizational problems ${ }^{(1)}$.

All of these implications, caused by unsafe practices in health, makes the issue of AEs turn into a public health problem, indicating the need to develop strategies for the monitoring of errors and improvements related to patient safety ${ }^{(2)}$. For safe strategies to be implemented in the interest of patient safety, it is necessary that health organizations adopt a safety culture model.

Safety culture can be defined as the set of individual and group values, attitudes, perceptions that determine the commitment and style, concerning questions related to patient safety in a health organization ${ }^{(3)}$.

In the literature, some instruments have been developed in order to measure the patient safety culture, through the health professionals' perception of the safety climate $^{(4)}$. The climate reflects the perception of professionals on safety issues at any given time in their workplace ${ }^{(5)}$. The climate is understood as the measurable part of the safety culture ${ }^{(5)}$.

Studies show that positive perceptions of the safety climate are associated with the adoption of safe behaviors, improved communication, conducting training programs, reduction of adverse events, among others, contributing to safe practices in patient care (4,6-7). $^{(2)}$

Other factors in the institutional and environmental spheres may be related to the adoption of the safety climate, such as professional stress, teamwork, job satisfaction, the institution's management structure and work conditions.

Researchers cite strengths and weaknesses that influence the implementation of a safety climate, based on the perception of nursing professionals. Among the factors that contributed to this implementation were: organizational change, professional training and development, relationship with patients, research and strategic planning The following weaknesses were highlighted: organization and infrastructure of the institution, shortcomings in communication and inefficiency of professional training with a safety focus ${ }^{(8)}$.
Thus, identifying factors that are associated with the patient safety climate is an important tool, capable of diagnosing factors that need improvement within health institutions and among professionals, guaranteeing safe and high-quality patient care. In addition, there is a clear lack of Brazilian studies using tools that measure hospitals' safety climate. Among the tools, the Safety Attitudes Questionnaire (SAQ), validated in Brazil in 2012, has been adopted in some Brazilian studies, being a valid and reliable tool that is considered one of the most sensitive and capable of assessing safety attitudes $^{(9)}$. Other studies are observed in the country assessing the safety climate, but with the use of other tools, such as the study conducted in the state of Paraná, in which the scale called "Safety Climate " was applied, translated and validated in $\mathrm{Brazi}^{(10)}$.

Based on the above, the aim of this research was to determine the association among patient safety scores, sociodemographic variables and health professionals.

\section{Method}

Observational and sectional study with a quantitative approach, undertaken at a large public teaching hospital that attends to high-complexity patients, located in the region of Triângulo Mineiro, Minas Gerais, Brazil.

Simple random samping was applied using the application Power Analysis and Sample Size (PASS), which considered a determination coefficient $R^{2}=0.02$ in a multiple linear regression model with four predictors, adopting a significance level or type I error of $\alpha=0.05$ and type II error of $\beta=0.2$. The sample consisted of 556 health professionals, including the nursing team (baccalaureate nurse, nursing technicians and auxiliary nurses), physicians, physiotherapists, social workers, speech, language and hearing therapists, laboratory, pharmacy and radiology technicians, dieticians, occupational therapists, pharmacists, health aids and psychologists. The data were collected between May and July 2013.

The study participants were health professionals who had worked at their services for at least one month, working at least 20 hours per week and who agreed to participate in the study by signing the Informed Consent Form. Professionals on medical leave or leave of absence during the data collection period and who could not be contacted after three attempts were excluded.

To collect the data, the tool called Safety Attitudes Questionnaire (SAQ) was used, validated for Brazilian Portuguese $^{(11)}$. The SAQ is divided in two parts. The 
first part contains 41 items and corresponds to six domains, divided in: Teamwork Climate, Satisfaction at Work, Perception of Service and Hospital Management, Safety Climate, Work Conditions and Perceived Stress. The response to each item follows a five-point Likert scale: disagrees completely (A), disagrees partially (B), neutral (C), agrees partially (D), agrees completely (E) and does not apply. The final score of the SAQ ranges between 0 and 100, with zero corresponding to the worst perceived safety climate and 100 to the best. According to the authors of the original tool, scores of 75 or higher are considered as positive(12).

The second part aims to collect sociodemographic and professional data (sex, professional category, length of experience in the specialty and work unit). In addition, other professional variables were added (activity sector, main and professional activity, time since graduation and length of experience at the institution, graduate degree and other employment). The professional's activity sectors were divided in accordance with Ministry of Health Decree 930, issued on August $27^{\text {th }} 1992^{(13)}$, which classifies the hospital areas according to the contamination potential as critical, semi-critical and non-critical.

The health team professionals received the data collection instrument for completion and return, with a preset deadline, after signing the Free and Informed Consent Form.

The data were included in an electronic worksheet in Excel $^{\circledR}$ for Windows $^{\circledR}$, validated using double data entry and exported to Statistical Package for the Social Sciences (SPSS), version 19.0 for Windows ${ }^{\circledR}$ for further processing and analysis.

To verify the patient's safety climate, initially, any reverse items in the tool were inverted and, then, the formula ( $m$ (q.1,q.2r,q.3, q.4,q.5, q.6,q.7, q.8,q.9, q.10,q. $\left.11 r_{,} . . q .41\right)$ )-1) $\times 25$ ) was applied, in which $m$ corresponds to the mean score of the items in the tool as a whole. The score in each domain was calculated based on the formula $(m-1) \times 25$, where $m$ is the mean item score in that domain, ranging in the interval [0-100].

In the preliminary bivariate analysis, Student's t-test was used (dichotomous categorical), variance analysis (ANOVA) for three or more categories and Spearman's correlation test for the ordinal variables. Associations were considered statistically significant when $\mathrm{p} \leq 0.05$.

Next, multiple linear regression was used to determine the predictors associated with the safety climate. Statistical significance was set at 0.05.

This study received Institutional Review Board approval under opinion 2306/2012, In compliance with Resolution 196/96 on research involving human beings ${ }^{(14)}$.

\section{Results}

\section{Sociodemographic and professional characteristics}

Among the 556 professionals who participated, the majority was female (426, 76.6\%); nursing team members $(401,72.1 \%)$; main activity involving adult patients $(300,54.0 \%)$; care functions only (393, 70.7\%); active in critical care area, according to contamination potential of hospital areas (287, $51.5 \%)$; without any graduate degree $(320,57.6 \%)$; and without any other employment contract (394, 70.9\%), according to Table 1.

As regards the length of experience in the specialty area, the largest proportion had between 5 and 10 years of experience, $(134,24.1 \%)$. Concerning the length of professional activity at the institution where the field study was carried out, between 11 and 20 years prevailed, (161, $29.0 \%$ ). What the time since graduation is concerned, more professionals had graduated between 11 and 20 years earlier, $(177,31.8 \%)$, according to Table 1.

Table 1 presents the research participants' $(n=556)$ sociodemographic and professional characteristics.

Table 1 - Sociodemographic and professional characteristics of research participants $(n=556)$. Uberaba, MG, Brazil, 2013

\begin{tabular}{lcc}
\hline Variables & $\mathbf{n}$ & $\%$ \\
\hline Sex & & \\
Male & 130 & 23.4 \\
Female & 426 & 76.6 \\
Professional categoryl & & 72.1 \\
Nursing team & 401 & 9.4 \\
Medical team & 52 & 18.5 \\
Other professionals & 103 & \\
\hline
\end{tabular}


Table 1 - (continuation)

\begin{tabular}{|c|c|c|}
\hline Variables & n & $\%$ \\
\hline \multicolumn{3}{|l|}{ Main activity } \\
\hline Adult & 300 & 54.0 \\
\hline Pediatric & 105 & 18.9 \\
\hline Both & 151 & 27.2 \\
\hline \multicolumn{3}{|l|}{ Professional activity } \\
\hline Care only & 393 & 70.7 \\
\hline Administrative only & 15 & 2.7 \\
\hline Both & 121 & 21.8 \\
\hline Not in direct contact with patient & 27 & 4.9 \\
\hline \multicolumn{3}{|l|}{ Activity sector } \\
\hline Critical area & 287 & 51.5 \\
\hline Semi-critical area & 242 & 43.8 \\
\hline Non-critical area & 27 & 4.9 \\
\hline \multicolumn{3}{|l|}{ Length of experience in specialty } \\
\hline Less than 6 months & 6 & 1.1 \\
\hline 6 to 11 months & 22 & 4.0 \\
\hline 1 to 2 years & 67 & 12.1 \\
\hline 3 to 4 years & 103 & 18.5 \\
\hline 5 to 10 years & 134 & 24.1 \\
\hline 11 to 20 years & 128 & 23.0 \\
\hline 21 years or more & 96 & 17.3 \\
\hline \multicolumn{3}{|l|}{ Length of work at the institution } \\
\hline Less than 6 months & 6 & 1.1 \\
\hline 6 to 11 months & 19 & 3.4 \\
\hline 1 to 2 years & 56 & 10.1 \\
\hline 3 to 4 years & 67 & 12.1 \\
\hline 5 to 10 years & 155 & 27.9 \\
\hline 11 to 20 years & 161 & 29.0 \\
\hline 21 years or more & 92 & 16.5 \\
\hline \multicolumn{3}{|l|}{ Time since graduation } \\
\hline Less than 6 months & 1 & 0.2 \\
\hline 6 to 11 months & 4 & 0.7 \\
\hline 1 to 2 years & 30 & 5.4 \\
\hline 3 to 4 years & 60 & 10.8 \\
\hline 5 to 10 years & 148 & 26.6 \\
\hline 11 to 20 years & 177 & 31.8 \\
\hline 21 years or more & 136 & 24.5 \\
\hline \multicolumn{3}{|l|}{ Graduate program } \\
\hline Yes & 236 & 42.4 \\
\hline No & 320 & 57.6 \\
\hline \multicolumn{3}{|l|}{ Type of graduate program } \\
\hline \multicolumn{3}{|l|}{ Lato sensu } \\
\hline Specialization & 203 & 36.5 \\
\hline \multicolumn{3}{|l|}{ Stricto Sensu } \\
\hline Master's & 27 & 4.9 \\
\hline Doctorate & 9 & 1.6 \\
\hline Post-doctorate & 1 & 0.2 \\
\hline Does not apply & 316 & 56.8 \\
\hline \multicolumn{3}{|l|}{ Other job contract } \\
\hline Yes & 162 & 29.1 \\
\hline No & 394 & 70.9 \\
\hline
\end{tabular}




\section{Descriptive analysis of Safety Attitudes Questionnaire scores}

The mean and median of the general score were $61.8(\mathrm{SD}=13.7)$ and 63.3, respectively. The higher the score, the better the professionals perceive the safety climate. According to the original authors of the SAQ, however, scores are considered positive when the total score is equal to or higher than 75 , indicating a negative general perception of the safety climate in this study.
Per domains, the mean (score) ranged between $52.4(\mathrm{SD}=19.5)$ and $80.5(\mathrm{SD}=17.7)$ and the median between 50.0 and 85.0. It was perceived that domain 5 , perception of unit and hospital management, showed the worst score (mean 52.4; SD=19.5), while domain 3 , satisfaction at work, showed the highest score (mean 80.5; $\mathrm{SD}=17.7$ ) among the professionals studied, according to Table 2 .

Table 2 shows the general and domain scores and descriptive analysis of the SAQ.

Table 2 - Descriptive analysis of general and domain scores of SAQ $(n=556)$. Uberaba, MG, Brazil, 2013

\begin{tabular}{|c|c|c|c|c|c|}
\hline \multirow{2}{*}{$\begin{array}{l}\text { Score } \\
\text { General }\end{array}$} & \multirow{2}{*}{$\begin{array}{r}\text { Mean } \\
61.8\end{array}$} & \multirow{2}{*}{$\begin{array}{c}\text { Median } \\
63.3\end{array}$} & \multicolumn{2}{|c|}{$\begin{array}{l}\text { Min-Max } \\
\text { Value }\end{array}$} & \multirow{2}{*}{$\begin{array}{c}\text { Standard Deviation } \\
13.7\end{array}$} \\
\hline & & & 10.9 & 95.7 & \\
\hline $\begin{array}{l}\text { Domain 1- Teamwork } \\
\text { climate }\end{array}$ & 68.3 & 70.8 & 4.17 & 100 & 19.0 \\
\hline $\begin{array}{l}\text { Domain 2- Safety } \\
\text { climate }\end{array}$ & 63.5 & 67.8 & 7.1 & 100 & 18.2 \\
\hline $\begin{array}{l}\text { Domain 3- Satisfaction } \\
\text { at work }\end{array}$ & 80.5 & 85.0 & 0 & 100 & 17.7 \\
\hline $\begin{array}{l}\text { Domain 4- Perceived } \\
\text { stress }\end{array}$ & 64.9 & 68.7 & 0 & 100 & 27.2 \\
\hline $\begin{array}{l}\text { Domain 5- Perception } \\
\text { of unit and hospital } \\
\text { management }\end{array}$ & 52.4 & 52.3 & 0 & 100 & 19.5 \\
\hline $\begin{array}{l}\text { Domain 6- Work } \\
\text { conditions }\end{array}$ & 53.5 & 50.0 & 0 & 100 & 26.3 \\
\hline
\end{tabular}

\section{Factors associated with the safety climate}

In the preliminary bivariate analysis, the variables that revealed statistically significant associations were: professional activity, professional category, length of professional activity, time since graduation and length of experience at the institution.

For the variable professional activity (care and non-care), the associations were significant for the domain perception of unit and hospital management $(p=0.01)$, where the non-care professionals obtained a better score than the professionals active in direct care.

As regards the professional category, statistically significant relations were found for the general score $(p=0.02)$, for the domain perception of unit and hospital management $(p=0.03)$ and the domain work conditions $(p=0.05)$. As perceived, the medical team's perception was better when compared to the nursing team category for these three variables.

What the variable length of professional activity is concerned, $p=0.01$ was found for the domain perceived stress, demonstrating that the professionals with less than six months of activity perceive the acknowledgement of stressful factors better.
For the variable time since graduation, significant associations were evidenced for the domains satisfaction at work $(p=0.005)$ and perceived stress $(p=0.005)$. Professionals with less than six months since graduation showed better perceptions in this domain when compared to the other categories.

For the variable length of experience at the institution, statistical significance was found in the domain satisfaction at work $(p=0.01)$ and perceived stress $(p=0.03)$. Professionals with 21 years of experience or more presented better perceptions when compared to the other professionals.

After the multivariate analysis through multiple linear regression, the sole statistically significant predictive variable $(p=0.01)$ associated with the SAQ scores was professional activity for the domain perception of unit and hospital management. In fact, this variable already demonstrated a significant association in the preliminary bivariate analysis. This result demonstrates that the non-care professionals (mean 58.0) show a better perception of the management when compared to the care professionals (mean 53.1), according to Table 3.

Table 3 shows the multiple linear regression analysis of the statistically significant variables in the bivariate analysis associated with the SAQ scores. 
Table 3 - Multiple linear regression of factors associated with SAQ scores of participating professionals $(n=556)$. Uberaba, MG, Brazil, 2013

\begin{tabular}{|c|c|c|c|c|c|c|c|c|c|c|c|c|c|c|}
\hline \multirow[t]{2}{*}{ Variables } & \multicolumn{2}{|c|}{ General Score } & \multicolumn{2}{|c|}{$\begin{array}{c}\text { Score } \\
\text { Dom. 1- } \\
\text { Safety climate } \\
\text { in team }\end{array}$} & \multicolumn{2}{|c|}{$\begin{array}{c}\text { Score } \\
\text { Dom. 2- } \\
\text { Safety climate }\end{array}$} & \multicolumn{2}{|c|}{$\begin{array}{c}\text { Score } \\
\text { Dom.3- } \\
\text { Satisfaction at } \\
\text { work }\end{array}$} & \multicolumn{2}{|c|}{$\begin{array}{l}\text { Score } \\
\text { Dom. 4- } \\
\text { Perceived } \\
\text { stress }\end{array}$} & \multicolumn{2}{|c|}{$\begin{array}{c}\text { Score } \\
\text { Dom. 5- } \\
\text { Perception } \\
\text { of unit and } \\
\text { hospital } \\
\text { management }\end{array}$} & \multicolumn{2}{|c|}{$\begin{array}{c}\text { Score } \\
\text { Dom. 6- } \\
\text { Work conditions }\end{array}$} \\
\hline & $\beta^{*}$ & $\mathbf{P}^{\dagger}$ & $\beta^{*}$ & $\mathbf{P}^{\dagger}$ & $\beta^{*}$ & $\mathbf{P}^{\dagger}$ & $\beta^{*}$ & $\mathbf{P}^{\dagger}$ & $\beta^{*}$ & $\mathbf{P}^{\dagger}$ & $\beta^{*}$ & $P^{\dagger}$ & $\beta^{*}$ & $\mathbf{P}^{\dagger}$ \\
\hline $\begin{array}{l}\text { Professional } \\
\text { activity }\end{array}$ & -0.07 & 0.07 & -0.06 & 0.13 & -0.01 & 0.78 & -0.03 & 0.39 & 0.05 & 0.23 & -0.10 & 0.01 & -0.04 & 0.25 \\
\hline Nursing team & -0.05 & 0.25 & 0.04 & 0.38 & 0.00 & 0.94 & -0.05 & 0.26 & -0.09 & 0.07 & -0.06 & 0.23 & -0.08 & 0.11 \\
\hline Medical team & 0.06 & 0.21 & 0.09 & 0.06 & -0.01 & 0.76 & -0.01 & 0.83 & 0.02 & 0.69 & -0.06 & 0.23 & -0.08 & 0.11 \\
\hline $\begin{array}{l}\text { Length of } \\
\text { experience }\end{array}$ & 0.03 & 0.51 & 0.00 & 0.91 & 0.02 & 0.73 & -0.03 & 0.53 & 0.01 & 0.75 & 0.05 & 0.36 & 0.07 & 0.22 \\
\hline $\begin{array}{l}\text { Length of work at } \\
\text { institution }\end{array}$ & 0.05 & 0.37 & -0.09 & 0.13 & -0.04 & 0.41 & 0.10 & 0.09 & 0.07 & 0.20 & -0.03 & 0.55 & -0.10 & 0.08 \\
\hline
\end{tabular}

$* \beta$ : Standardized regression coefficient; $+P$ : $P$ value.

\section{Discussion}

The patient safety climate score in this study obtained a mean score of $61.8(\mathrm{SD}=13.7)$ and a median score of 63.3. In the literature, studies were found whose mean scores were also inferior to the acceptable score of $75^{(15-18)}$. It is highlighted that scores inferior to 60 are considered a sign of alert for health organizations, indicating the urgent need to promote the safety climate at the institution ${ }^{(11)}$.

In this research, the variable professional activity (care and non-care) was considered a predictive variable for the domain perception of unit and hospital management $(p=0.01)$. In line with this finding, a study developed to identify the safety climate in hospitals in the USA found significant associations between care and management professionals, demonstrating that management professionals had a more positive perception than care professionals ${ }^{(19)}$.

A study involving outpatient professionals in Texas, USA also found significant differences between professional activity (care and non-care) and the SAQ domains. That study demonstrated that, for the domain perception of unit and hospital management, the management (non-care) professionals obtained better scores when compared to the medical professionals ${ }^{(20)}$, demonstrating the non-care professionals' better perception of management actions than patient safety issues.

The findings of a study involving health professionals at a hospitalization unit of a teaching hospital in Ireland demonstrates that the nurse managers obtained higher scores for the domains teamwork climate $(p<0.05)$ and safety climate $(p<0.01)$ than the care professionals ${ }^{(18)}$.
Authors suggest that the better perception among management than among care professionals can be explained by the managers' sense of propriety and responsibility regarding their roles in the hospital infirmaries. In addition, the care professionals may feel excluded from administrative decision processes, besides their lack of participation in the elaboration and implementation of strategies, reducing their autonomy and generating dissatisfaction with management actions $^{(18)}$.

Another explanation for these findings can be related to the care professionals' experience with safety risks, making them display worse perceptions of the management, as these professionals have less contact with direct patient care. In addition, there is a culture of hiding negative information (occurrence of errors, incidents and adverse events) among the professionals, making it difficult for the safety problems to reach the hospital management. Another aspect appointed is related to the management professionals' desire to be considered as an organization committed to safety, making them display positive perceptions ${ }^{(19)}$. This situation can turn into a problem though when this positive view does not reflect the true institutional reality ${ }^{(20)}$.

In the literature, however, studies were found that identified other predictors of the patient safety climate. The most mentioned predictors are the professionals' age, sex and professional category ${ }^{17,21-22)}$.

Hospitals in Cyprus, Greece found that the variables age and reported fatigue at work were considered predictors of the domains teamwork climate, safety climate and work conditions ${ }^{(17)}$.

A study aimed at verifying the relation between sex and perceived safety culture found that the eldest 
professionals' perceived teamwork climate was better than the youngest; and that the male sex obtained better perceptions of satisfaction at work and work conditions when compared to the female sex ${ }^{(21)}$.

In a study undertaken at obstetric centers in the USA, statistically significant associations were found between the domain teamwork climate and professional category, with physicians showing better scores than nurses ${ }^{(22)}$. That study demonstrated different viewpoints and opinions among physicians and nurses regarding safety issues, with physicians demonstrating greater awareness in reports on potential damage when compared to nurses ${ }^{(22)}$.

This study is limited by the fact that, although simple random sampling was used to obtain the sample size, the cross-sectional cohort to obtain the data may limit the spectrum of the analysis. Nevertheless, the proposed objectives were reached. Therefore, longitudinal studies are suggested for the future.

\section{Conclusion}

As observed, the general score was $61.8(\mathrm{SD}=13.7)$ and the median 63.3, demonstrating the professionals' negative perception of the patient safety climate.

In the bivariate analysis, the variables that showed statistically significant associations were: professional activity for the domain perception of unit and hospital management $(p=0.01)$; professional category for the general score $(p=0.02)$, for the domain perception of unit and hospital management $(p=0.03)$ and for the domain work conditions $(p=0.05)$; the variable length of professional activity for the domain perceived stress $(p=0.01)$; the variable time since graduation for the domains satisfaction at work $(p=0.005)$ and perceived stress $(p=0.005)$; and the variable length of experience at the institution for the domain satisfaction at work $(p=0.01)$ and perceived stress $(p=0.03)$. Nevertheless, the professional activity was considered the predictive variable for the domain perception of unit and hospital management, with non-care professionals showing a better perception than care professionals.

The identification of the predictors of patient safety scores is an important tool that, linked with organizational actions, permits diagnosing, intervening and executing activities, based on the domains that need to be improved (work conditions and management actions) and the professionals' intrinsic and extrinsic factors in need of attention (stress, teamwork and satisfaction). All of these efforts contribute to implement the safety climate at the institution, with the promotion of patient safety as the final result.

\section{References}

1. Kho ME, Perri D, McDonald E, Waugh L, Orlicki C, Monaghan E, et al. The climate of patient safety in a Canadian intensive care unit. J Crit Care. 2009;24(3):7-13.

2. Dias MAE, Martins M, Navarro N. Rastreamento de resultados adversos nas internações do Sistema Único de Saúde. Rev Saúde Pública. 2012;46(4):719-29.

3. Nieva VF, Sorra J. Safety culture assessment: a tool for improving patient safety in healthcare organizations. Qual Saf Health Care. 2003;2(Suppl 2):17-23.

4. Lee WC, Wung HY, Liao HH, Lo CM, Chang FL, Wang PC, et al. Hospital safety culture in Taiwan: a nationwide survey using Chinese version safety attitude questionnaire. BMC Health Serv Res. 2010;10:1-8.

5. Sexton JB, Helmreich RL, Neilands TB, Rowan K, Vella K, Boyden J, et al. The Safety Attitudes Questionnaire: psychometric properties, benchmarking data, and emerging research. BMC Health Serv Res. 2006;44(6):1-10.

6. Alahmadi HA. Assessment of patient safety culture in Saudi Arabian hospitals. Qual Saf Health Care. 2010;9(17):1-5.

7. El-Jardali F, Dimassi H, Jamal D, Jaafar M, Hemadeh $\mathrm{N}$. Predictors and outcomes of patient safety culture in hospitals. Qual Saf Health Care. 2011;11(45):4-12.

8. Ques AAM, Montoro CH, Gonzáles MG. Strengths and threats regarding the patient's safety:nursing professionals' opinion. Rev. Latino-Am. Enfermagem. 2010;18(3): 339-45.

9. Colla JB, Bracken AC, Kinney LM, Weeks WB. Measuring patient safety climate: a review of surveys. Qual Saf Health Care. 2005;14(5):364-6.

10. Ribeiro PHV, Brevidelli MM, Tipple AFV, Ribeiro RP, Gir E. Clima de segurança organizacional e a adesão às precações padrão entre dentistas. Acta Paul. Enferm. 2013;26(2):192-7.

11. Carvalho REFL, Cassiani SHB. Cross-cultural adaptation of the Safety Attitudes Questionnaire - Short Form 2006 for Brazil. Rev. Latino-Am. Enfermagem. 2012; 20(3):575-82.

12. Sexton JB, Thomas EJ, Grillo SP. The safety attitudes questionnaire (SAQ) Guidelines for administration. The University of Texas Center of Excellence for Patient Safety Research and Practice; 2003. Technical Report. Sponsored by the Agency for Healthcare Research and Quality. 
13. Lei n 9962, de 22 de Fevereiro de 2000 (BR). Resolve expedir normas para controle das infecções hospitalares. Diário Oficial da União, Brasília n. 38, Seção 1, p. 35, 23 fev. 2000.

14. Conselho Nacional de Saúde (BR). Resolução 196, de 10 de outubro de 1996. Brasília: CNS; 1996.

15. Davenport DL, Henderson WG, Hogan $S$, Mentzer RM Jr, Zwischenberger JB. Surgery resident working conditions and job satisfaction. Surgery. 2008; 144(2):332-8.

16. Modak I, Sexton JB, Thomas RL, Helmreich RL, Thomas EJ. Measuring safety culture in the ambulatory settings: the safety attitudes questionnaire - ambulatory version. J Gen Intern Med. 2007;22(1):1-5.

17. Raftopoulos V, Savva N, Papadopoulou M. Safety culture in the maternity units: a census survey using the safety attitudes questionnaire. BMC Health Serv Res. 2011; 11(Suppl. 1):1-10.

18. Relihan E, Glynn S, Daly D, Silke B, Ryder S. Measuring and benchmarking safety culture: application of the safety attitudes questionnaire to an acute medical admissions unit. Ir J Med Sci. 2009;178(4):433-9.

19. Singer SJ, Fawell A, Gaba DM, Baker LC. Patient safety climate in US hospitals: variation by management level. Med Care. 2008;46(11):1149-56.

20. Thomas E J, Sexton JB, Helmreich EL. Discrepant attitudes about teamwork among critical care nurses and physicians. Crit Care Med. 2003;31(1):956-59.

21. Carney BT, Mills PD, Bagian JP, Weeks WB. Sex differences in operating room care giver perceptions of patient safety: a pilot study from the Veterans Health Administration Medical Team Training Program. Qual Saf Health Care. 2010;19(2): 128-31.

22. Lyndon A, Sexton JB, Simpson KR, Rosenstein A, Lee $K A$, Wachter RM. Predictors of likelihood of speaking up about safety concerns in labour and delivery. BMJ Qual Saf. $2011 ; 22(2): 791-9$. 